\title{
PRO-ARTE: \\ Proyecto que compatibiliza turismo y patrimonio mediante un desarrollo sostenido
}

Desde la Dirección General de Formación Profesional y Empleo de la Consejería de Trabajo e Industria y El Instituto Andaluz de la Mujer se está llevando a cabo el Proyecto "Conéctate al Empleo en el marco de la Iniciativa Comunitaria Empleo-Now".

PRO-ARTE, nace con el fin de promover la inserción laboral de veinte mujeres del ámbito rural, de las provincias de Sevilla y Almería, mediante la creación de empresas turísticas relacionadas con el patrimonio monumental, artístico, natural y etnográfico.

En el mundo rural los cambios en los sistemas de producción y el empobrecimiento del sector agrícola han supuesto la despoblación de estas zonas y la pérdida de oportunidades de empleo para la población en general, pero especialmente para la mujer, que ve reducida su actividad cada vez más en ámbito doméstico. En la actualidad, es perceptible el interés creciente, por parte de la población por volver a los ambientes rurales, lo que está propiciando el llamado Turismo Alternativo. A su vez, la toma de conciencia sobre la existencia de un Patrimonio y su reconocimiento ha contribuido a la propuesta de actividades turísticas culturales. Estas actividades turísticas no son sólo motor de desarrollo local, en cuanto generan empleo y promueven la economía, sino que sirven a fines como los de conocer y difundir este Patrimonio.

De este modo PRO-ARTE, promueve la creación de empresas turísticas sin olvidar que el diálogo, entre los sectores del turismo y de la cultura, es necesario para el futuro sostenible de nuestro Patrimonio.

La génesis del proyecto se remonta a Abril de 1998, dónde se designa al equipo técnico para la preparación y puesta en marcha del mismo. Desde entonces se han contemplado varias acciones:

- Determinación del perfil competencial de Agente Cultural y de Dinamizadora Cultural según la metodología del INEM.

- Elaboración de material didáctico sobre patrimonio, turismo, creación de empresas y animación sociocultural y sobre la relación existente entre ellos, para las Agentes Culturales y Dinamizadoras Culturales.

- Selección de diez beneficiarias por provincia. Estas mujeres como empresarias y Dinamizadoras Culturales, mediante la creación de sus empresas, no sólo son fuentes que generan movimiento socieconómico en su zona sino que colaboran en la concienciación, puesta en valor y reconocimiento de nuestro Patrimonio.

PRO-ARTE contempla además una serie de acciones con las Dinamizadoras Culturales:

- Una primera fase de formación que se recoge en el material didáctico, donde a parte de tratar cuestiones históricas, legales y técnicas se pretende aunar criterios y conceptos sin olvidar y asumiendo el espíritu del proyecto: el desarrollo sostenido. A partir de esta formación, mediante la capacitación de estas mujeres para identificar y catalogar los recursos patrimoniales, se contempla la realización de un inventario de estos recursos a fin de generar proyectos empresariales o perfilar los ya existentes.

- Elaboración de un cuaderno de seguimiento para la inserción laboral en el sector turístico, el cual servirá como material de trabajo y agenda-guía en las labores de orientación profesional y, por supuesto, en las iniciativas de inserción laboral tanto por cuenta ajena como por cuenta propia.

- Asesoramiento técnico y acompañamiento permanente para la elaboración de los planes de empresa y seguidamente la constitución, puesta en marcha y consolidación de los distintos proyectos empresariales.

- Edición en soporte escrito de catálogos provinciales con la finalidad de promocionar y difundir los bienes culturales de las áreas de actuación a la vez que las distintas iniciativas empresariales generadas.

- La última fase del proyecto contempla la comercialización de las distintas empresas mediante la negociación con los profesionales del turismo a fin de insertar las nuevas empresas en el sector.

En este sentido, es importante destacar el papel que cada una de las Dinamizadoras está desempeñando, puesto que son las verdaderas protagonistas de PRO-ARTE, al constituirse en Dinamizadoras de su entorno más próximo; así como en la generación de su propio empleo.

$M^{a}$ Dolores Ortiz Coordinadora del Proyecto Proarte 